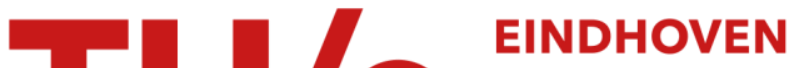 UNIVERSITY OF TECHNOLOGY
}

\section{Why are some titanium silicalite-1 samples active and others not?}

Citation for published version (APA):

vd Pol, A. J. H. P., Verduijn, A. J., \& Hooff, van, J. H. C. (1992). Why are some titanium silicalite-1 samples active and others not? Applied Catalysis. A, General, 92(2), 113-130. https://doi.org/10.1016/0926$860 \times(92) 80310-9$

DOI:

10.1016/0926-860X(92)80310-9

Document status and date:

Published: 01/01/1992

\section{Document Version:}

Publisher's PDF, also known as Version of Record (includes final page, issue and volume numbers)

\section{Please check the document version of this publication:}

- A submitted manuscript is the version of the article upon submission and before peer-review. There can be important differences between the submitted version and the official published version of record. People interested in the research are advised to contact the author for the final version of the publication, or visit the $\mathrm{DOI}$ to the publisher's website.

- The final author version and the galley proof are versions of the publication after peer review.

- The final published version features the final layout of the paper including the volume, issue and page numbers.

Link to publication

\section{General rights}

Copyright and moral rights for the publications made accessible in the public portal are retained by the authors and/or other copyright owners and it is a condition of accessing publications that users recognise and abide by the legal requirements associated with these rights.

- Users may download and print one copy of any publication from the public portal for the purpose of private study or research.

- You may not further distribute the material or use it for any profit-making activity or commercial gain

- You may freely distribute the URL identifying the publication in the public portal.

If the publication is distributed under the terms of Article 25fa of the Dutch Copyright Act, indicated by the "Taverne" license above, please follow below link for the End User Agreement:

www.tue.nl/taverne

Take down policy

If you believe that this document breaches copyright please contact us at:

openaccess@tue.nl

providing details and we will investigate your claim. 


\title{
Why are some titanium silicalite-1 samples active and others not?
}

\author{
A.J.H.P. van der Pol, A.J. Verduyn and J.H.C. van Hooff \\ Eindhoven University of Technology, Laboratory of Inorganic Chemistry and Catalysis, \\ P.O. Box 513, 5600 MB Eindhoven (Netherlands)
}

(Received 15 June 1992, revised manuscript received 11 September 1992)

\begin{abstract}
Titanium silicalite-1 samples of different particle size are synthesized. X-ray diffraction (XRD), infrared (IR), ${ }^{29} \mathrm{Si}$ magic angle spinning nuclear magnetic resonance (MAS NMR), diffuse reflectance electron absorption spectrometry (DREAS), thermogravimetric analysis (TGA), pore volume and particle size measurements are used to characterize these samples. In the hydroxylation of phenol with hydrogen peroxide large differences in activity are found between different TS-1 samples. Using XRD, IR, ${ }^{29} \mathrm{Si}$ MAS NMR, and DREAS measurements it is impossible to differentiate between active and less active samples. Particle size determination (directly by scanning electron microscopy (SEM), Coulter Counter, and Malvern and indirectly by TGA and adsorption measurements) however can explain these differences. Smaller particles are more active than larger particles. From calculations of the Weisz modulus it can be concluded that large zeolite particle are not fully utilized because of pore diffusion limitations. The product distribution is also influenced by particle size.
\end{abstract}

Keywords: diffusion limitations, phenol hydroxylation, titanium silicalite-1, TS-1, zeolites.

\section{INTRODUCTION}

Titanium silicalite-1 (TS-1) has been developed in 1983 by research workers of Enichem [1]. This zeolite shows several very interesting properties in heterogeneous oxidation catalysis. TS-1 shows good activity and selectivity in alcohol oxidation $[2,3]$, alkane oxidation $[4,5]$, alkene epoxidation [6-8] and ammoximation of cyclohexanone to cyclohexanone oxime [9]. The hydroxylation of phenol to catechol and hydroquinone has already been commercialized by Enichem in 1986. The hydroxylation process with TS-1 is superior to other processes because of the decrease of tar formation and other polluting by-products $[10,11]$.

Correspondence to: Dr. A.J.H.P. van der Pol, Eindhoven University of Technology, Laboratory of Inorganic Chemistry and Catalysis, P.O. Box 513, 5600 MB Eindhoven, Netherlands. Tel. (+3140)474952, fax. (+31-40)455054, e-mail: TGTAMP@CHEM.TUE.NL. 
These facts have attracted the attention of several other groups who also started research in this field. At first, TS-1 samples had to be prepared according to the methods as described by Enichem. Later a modified procedure developed by Thangaraj et al. [12] became available. At first, the phenol hydroxylation activity of self-made TS-1 catalysts, was often much lower than that reported in the literature. This problem was encountered by several research groups and we were also confronted with it. The self-made TS-1 samples had the same X-ray diffraction (XRD), infrared (IR) and ${ }^{29} \mathrm{Si}$ magic angle spinning (MAS) nuclear magnetic resonance (NMR) spectra as reported in the literature, but generally the product yield was much lower than mentioned in the patent literature. This led to the conclusion that it is impossible to distinguish between active and less active TS-1 samples by the characterization techniques used in the patent literature. So there must be another characteristic that strongly influences the catalytic properties of TS-1. The objective of this paper is to show that particle size is that characteristic.

\section{EXPERIMENTAL}

\section{Preparation of TS-1 samples}

A large number of TS-1 samples were prepared according to method 1 as described in the Enichem patent [1]. The complete results of this investigation will be published separately [13]. In this paper we will focus our attention on four representative samples out of this series. The chemical composition of the crystallization mixtures used for the preparation of these samples is mentioned in Table 1.

Crystallization was carried out at $175^{\circ} \mathrm{C}$ for 12 days under stirred conditions $(120 \mathrm{rpm})$. The obtained crystallization products were washed, dried and finally calcined at $550^{\circ} \mathrm{C}$ in the laboratory air for three hours prior to the use as catalyst.

\section{TABLE 1}

Chemical composition of the crystallization mixtures used for the preparation of TS-1 samples 1 to 4 (molar ratio)

\begin{tabular}{lllrl} 
Sample & TEOS $^{a}$ & TEOT $^{b}$ & TPAOH $^{c}$ & $\mathrm{H}_{2} \mathrm{O}$ \\
\hline 1 & 33.3 & 1 & 11.6 & 933 \\
2 & 31.6 & 1 & 7.0 & 880 \\
3 & 33.9 & 1 & 18.0 & 950 \\
4 & 30.2 & 1 & 23.6 & 850
\end{tabular}

a TEOS: tetraethyl orthosilicate $\left(\mathrm{Si}\left(\mathrm{OC}_{2} \mathrm{H}_{5}\right)_{4}\right.$, Merck).

${ }^{b}$ TEOT: tetraethyl orthotitanate $\left(\mathrm{Ti}\left(\mathrm{OC}_{2} \mathrm{H}_{5}\right)_{4}\right.$, Merck).

' TPAOH: tetrapropyl ammonium hydroxide $\left(\mathrm{N}\left(\mathrm{C}_{3} \mathrm{H}_{7}\right)_{4} \mathrm{OH}\right.$, Alfa Products $)$. 


\section{Characterization of TS-1 samples}

The crystallization products were identified by X-ray powder diffraction using a Philips PW 7200 diffractometer (with $\mathrm{Cu} \mathrm{K} \alpha$ radiation of $1.5418 \mathrm{~A}$ ). The spectra were recorded between $2 \theta=5^{\circ}$ and $2 \theta=50^{\circ}$ and a scanning rate of $4^{\circ}$ per minute was used.

The infrared spectra of the formed products were obtained using the $\mathrm{KBr}$ wafer technique in a Hitachi 270-50 infrared spectrophotometer. An amount of $2 \mathrm{mg}$ of zeolite was mixed with $600 \mathrm{mg} \mathrm{KBr}$ and a pellet of $200 \mathrm{mg}$, with a diameter of $1 \mathrm{~cm}$, was pressed at 10 tons $/ \mathrm{cm}^{2}$. The IR spectra were recorded between 400 and $1300 \mathrm{~cm}^{-1}$.

${ }^{29} \mathrm{Si}$ MAS NMR spectra were recorded on a Brucker CXP 300 spectrometer at a frequency of $59.63 \mathrm{MHz}$ and a spinning rate of ca. $3 \mathrm{KHz}$.

Diffuse reflectance electron absorption spectrometry (DREAS) was done with a Hitachi 150-20 spectrophotometer.

The titanium content of the samples was determined by atomic absorption spectroscopy using an Perkin-Elmer 3030 atomic absorption spectrophotometer.

Particle sizes and morphology were determined by using a JEOL 840-A scanning electron microscope with an EDX analyzer. Particle size was also determined by using a Malvern particle sizer and a Coulter Counter TA II.

Thermogravimetric analysis (TGA) experiments and adsorption measurements were carried out in a Setaram TG-85 model 16-18 system.

\section{Catalytic testing of the TS-1 samples}

The hydroxylation of phenol (see reaction scheme) was used as test reaction for the catalytic properties of the TS-1 samples 1 to 4 .

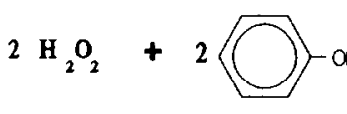

PHENंOL

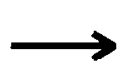

HYDROCHINON

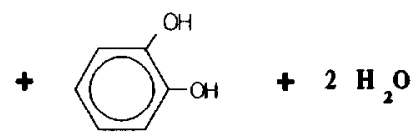

CATECHOL

The reaction was performed in a $100 \mathrm{ml}$ stirred batch reactor using $10 \mathrm{~g}$ phenol, $10 \mathrm{ml}$ acetone and $0.5 \mathrm{~g}$ of catalyst, at reflux conditions $\left(\mathrm{ca} .80^{\circ} \mathrm{C}\right.$ ). At the beginning of the reaction $2 \mathrm{ml}$ of $35 \mathrm{wt}$.- $\% \mathrm{H}_{2} \mathrm{O}_{2}$, was added to the reaction mixture and the reaction was monitored by taking small $(0.2 \mathrm{ml})$ samples at different times. The reaction products were analyzed by high-performance liquid chromatography (HPLC). A reversed phase column (RP-18, Chrompack) with methanol/water $(10 / 90,1 \mathrm{ml} / \mathrm{min})$ as eluent was used. Detection was done by a UV double wavelength detector at 220 and $243 \mathrm{~nm}$. Sometimes the reaction products were also analyzed by gas chromatography (GC) to check 
that no compounds were missed in the HPLC analysis. The decrease of the hydrogen peroxide concentration was monitored by standard iodometric titration.

\section{RESULTS AND DISCUSSION}

The TS- 1 samples 1 to 4 were first characterized by the standard characterization methods.

\section{$X$-ray diffraction}

The X-ray diffractograms showed in all four cases the pattern typical for a highly crystalline zeolite having a MFI structure, with only marginal differences in position and intensity.

\section{Infrared}

The IR spectra of the four TS-1 samples are presented in Fig. 1. In all four cases the peak at $960 \mathrm{~cm}^{-1}$, typical for TS-1, is present at approximately the same intensity.

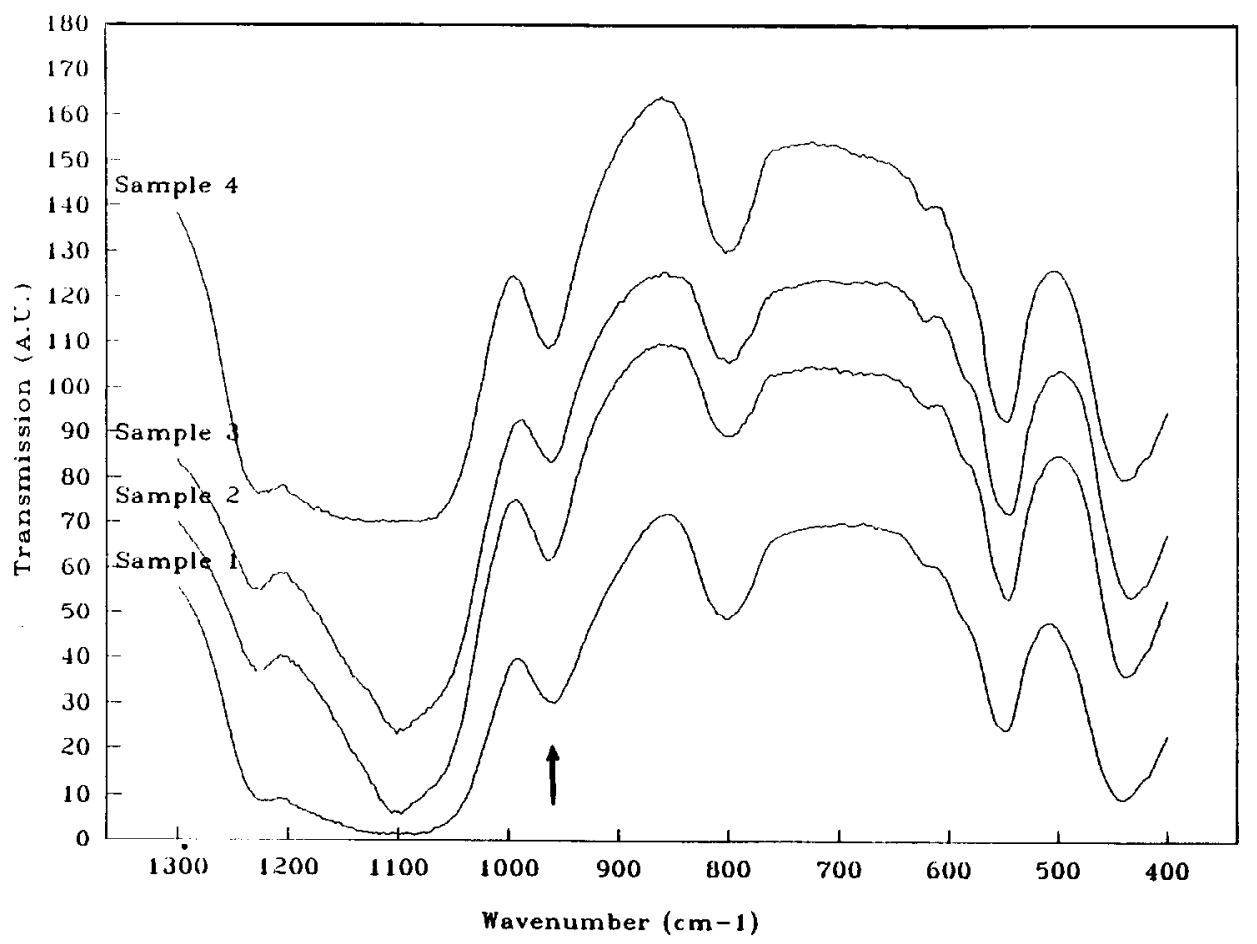

Fig. 1. IR spectra of the four TS-1 samples. 


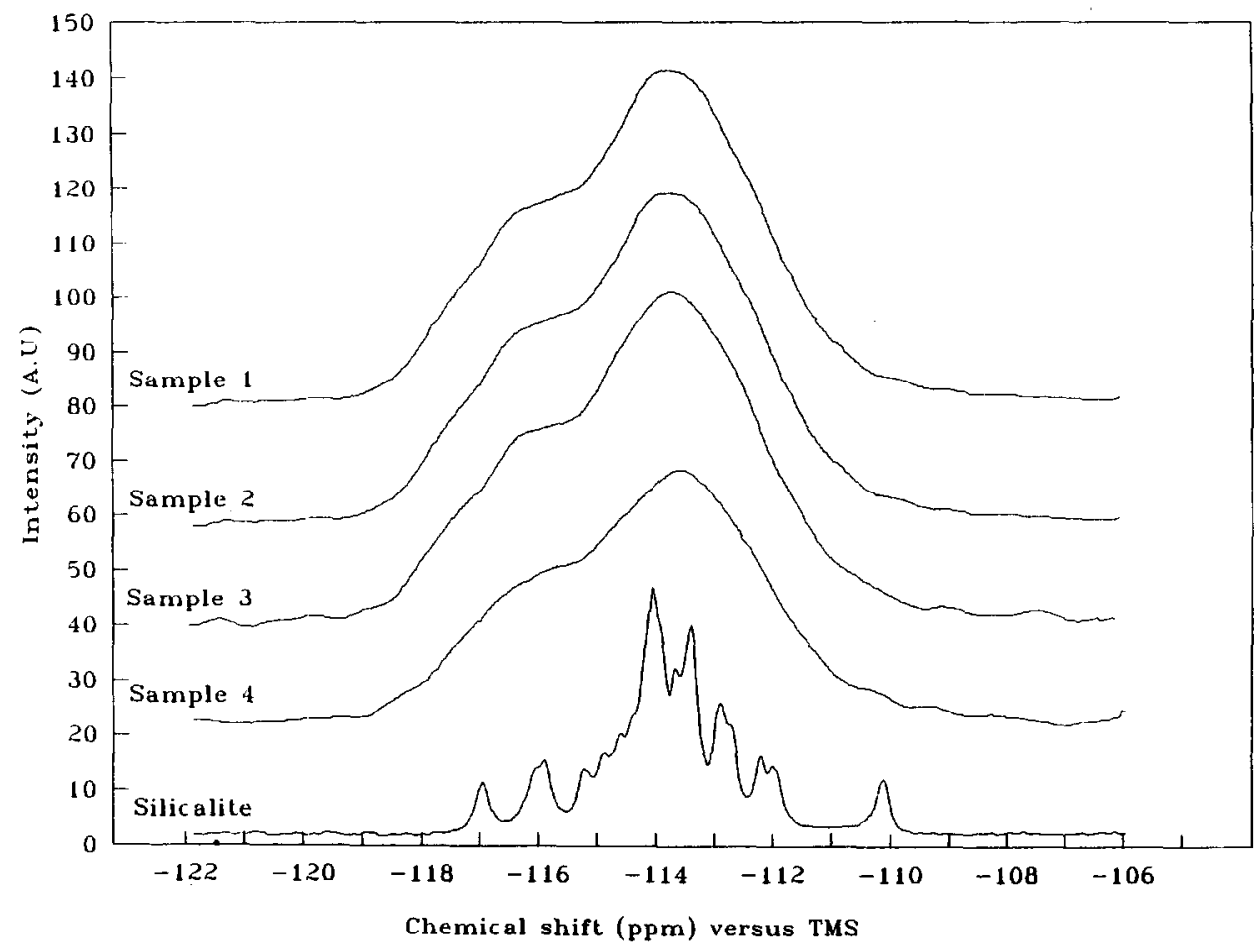

Fig. 2. NMR spectra of calcined silicalite-1 and the four calcined TS-1 samples. Pulse length $4 \mu$ s, pulse interval $10 \mathrm{~s}$, number of scans 144.

\section{Nuclear magnetic resonance}

The ${ }^{29} \mathrm{Si}$ MAS NMR spectra of the four TS-1 samples together with the spectrum of silicalite-1 are presented in Fig. 2. Instead of the structured spectrum of silicalite- 1 the TS-1 samples are characterized by a broad signal with a shoulder on the high-field side, with only little difference between the four spectra. We note here that we observed this shoulder also in silicalite-1 (without any titanium) which has a high amount of defects in its structure. Therefore a broad ${ }^{29} \mathrm{Si}$ MAS NMR signal with a shoulder on the high-field side is no direct prove of the incorporation of titanium into ZSM-5, but it is, on the other hand, always found if titanium is incorporated. The difference in the ${ }^{29} \mathrm{Si}$ MAS NMR spectra between the different TS-1 samples is nil.

\section{Diffuse reflectance electron absorption spectrometry}

The diffuse reflectance electron absorption spectra of the four TS-1 samples are presented in Fig. 3. From literature [14] it is known that the absorption around $48000 \mathrm{~cm}^{-1}$ is related to $\mathrm{Ti}^{4+}$ four-fold surrounded, while the presence 


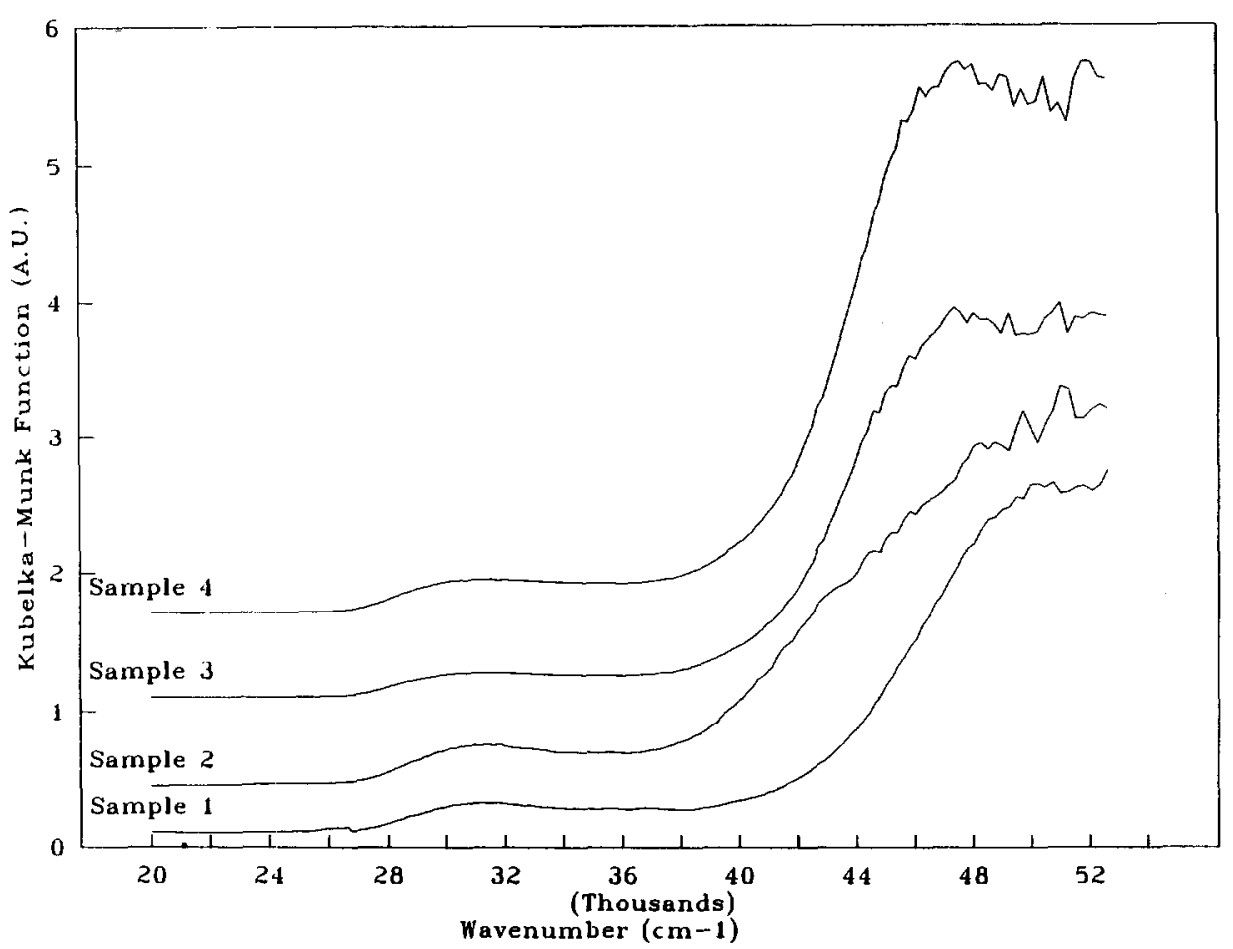

Fig. 3. DREAS spectra of the four TS-1 samples.

of six-fold surrounded $\mathrm{Ti}^{4+}$ will result in absorption around $42000 \mathrm{~cm}^{-1}$. It should be noted that the amount of six-fold surrounded titanium is also influenced by the absorption of water at the titanium centre, because water can be inserted into a four-fold surrounded titanium, giving titanium an octahedral surrounding [14]. The experimental DREAS spectra presented in Fig. 3 give no reason to suppose large differences between the four TS-1 samples.

\section{Atomic absorption spectroscopy}

The titanium content as determined by atomic absorption spectroscopy (AAS) of all four TS-1 samples was found to be equal to $2.8 \pm 0.3 \mathrm{~mol}-\%$, which corresponds to a $\mathrm{Ti} /(\mathrm{Si}+\mathrm{Ti})$ ratio of approximately 0.035 .

So from the standard characterization techniques it may be concluded that the TS-1 samples 1 to 4 are very similar; and so similar catalytic properties would be expected.

\section{Catalytic activity}

The results of the catalytic activity tests of these TS- 1 samples are presented in Fig. 4 and Table 2. In Fig. 4 the formation of the dihydroxybenzenes (hy- 


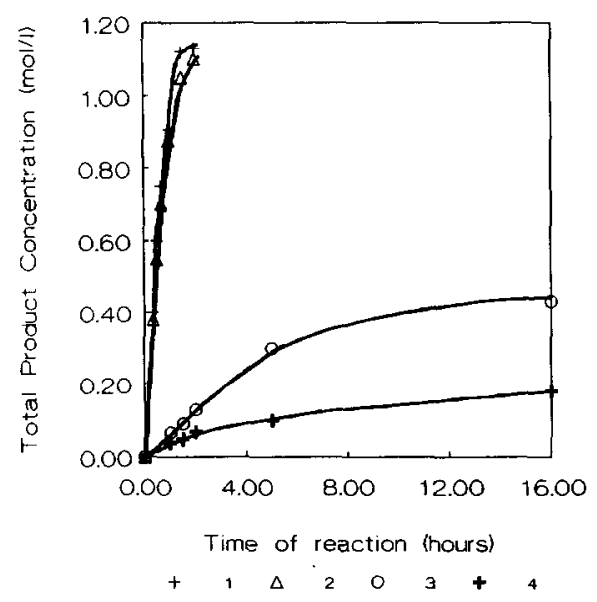

Fig. 4. Total product concentration versus time of reaction for TS-1 samples 1 to 4 .

\section{TABLE 2}

Catalytic properties of TS-1 samples 1 to 4 in the hydroxylation of phenol

\begin{tabular}{lclcl}
\hline Sample & $R_{0}{ }^{a}$ & $\begin{array}{l}\text { Conv. }^{b} \\
(\%)\end{array}$ & $\begin{array}{l}\text { Sel. }^{c} \\
(\%)\end{array}$ & $\begin{array}{l}\text { Yield }^{d} \\
(\%)\end{array}$ \\
\hline 1 & 10.2 & 50 & 95 & 93 \\
2 & 9.00 & 44 & 93 & 92 \\
3 & 1.07 & 6 & 15 & 40 \\
4 & 0.46 & 2.5 & 8 & 18 \\
\hline
\end{tabular}

${ }^{a} R_{0}$ initial reaction rate of dihydroxy benzene formation $\left(\mathrm{mol} / \mathrm{m}^{3} \mathrm{~s}\right.$ ).

${ }^{b} \mathrm{H}_{2} \mathrm{O}_{2}$ conversion at $t=1 \mathrm{~h}$.

c Moles dihydroxybenzene $/$ moles of reacted $\mathrm{H}_{2} \mathrm{O}_{2} \cdot 100 \%$ at $t=1 \mathrm{~h}$.

${ }^{d}$ Moles dihydroxy benzene/moles of $\mathrm{H}_{2} \mathrm{O}_{2}$ added $\cdot 100 \%$ at complete $\mathrm{H}_{2} \mathrm{O}_{2}$ conversion.

droquinone and catechol) as a function of time of reaction is shown. From this it can be easily seen that the four TS-1 samples possess strongly different catalytic properties. Formation of hydroquinone plus catechol is much faster with TS- 1 samples 1 and 2 than with samples 3 and 4 . This behaviour is further specified in Table 2 in which the initial rate of dihydroxybenzene formation, the hydrogen peroxide conversion, the dihydroxybenzene selectivity after $1 \mathrm{~h}$ of reaction, and the dihydroxybenzene yield at complete $\mathrm{H}_{2} \mathrm{O}_{2}$ conversion are listed.

These figures show large differences between the catalytic properties of the four TS-1 samples that are, according to the standard characterization techniques, very similar. So there must be another characteristic that strongly influences the catalytic properties. 
As the catalytic reaction is carried out in the liquid phase at relatively low temperatures, the diffusion of the reactant and reaction products will have a considerable influence on the observed reaction rate, and if this supposition is true catalyst texture (particle size and morphology) will be very important.

To check whether differences in catalyst texture are responsible for the observed differences in catalytic properties five additional characterization techniques were applied.

\section{Scanning electron microscopy}

Firstly scanning electron microscopy (SEM) was used to obtain information about catalyst particle size and morphology. A representative SEM picture of TS-1 sample 1 is shown in Fig. 5. This picture clearly shows that the applied crystallization method led to a very homogeneous product, consisting of particles of about $0.2 \mu \mathrm{m}$ in size. Comparable pictures were obtained for the TS-1 samples 2,3 and 4, also showing very homogeneous products but with clearly different particle sizes. This observation is illustrated in Fig. 6 in which representative SEM pictures of TS-1 samples 1, 2, 3 and 4 are shown. From this figure it can be clearly seen that the average particle size of samples 1 and 2 is much smaller ( 0.2 and $0.3 \mu \mathrm{m}$, respectively) than the average particle size

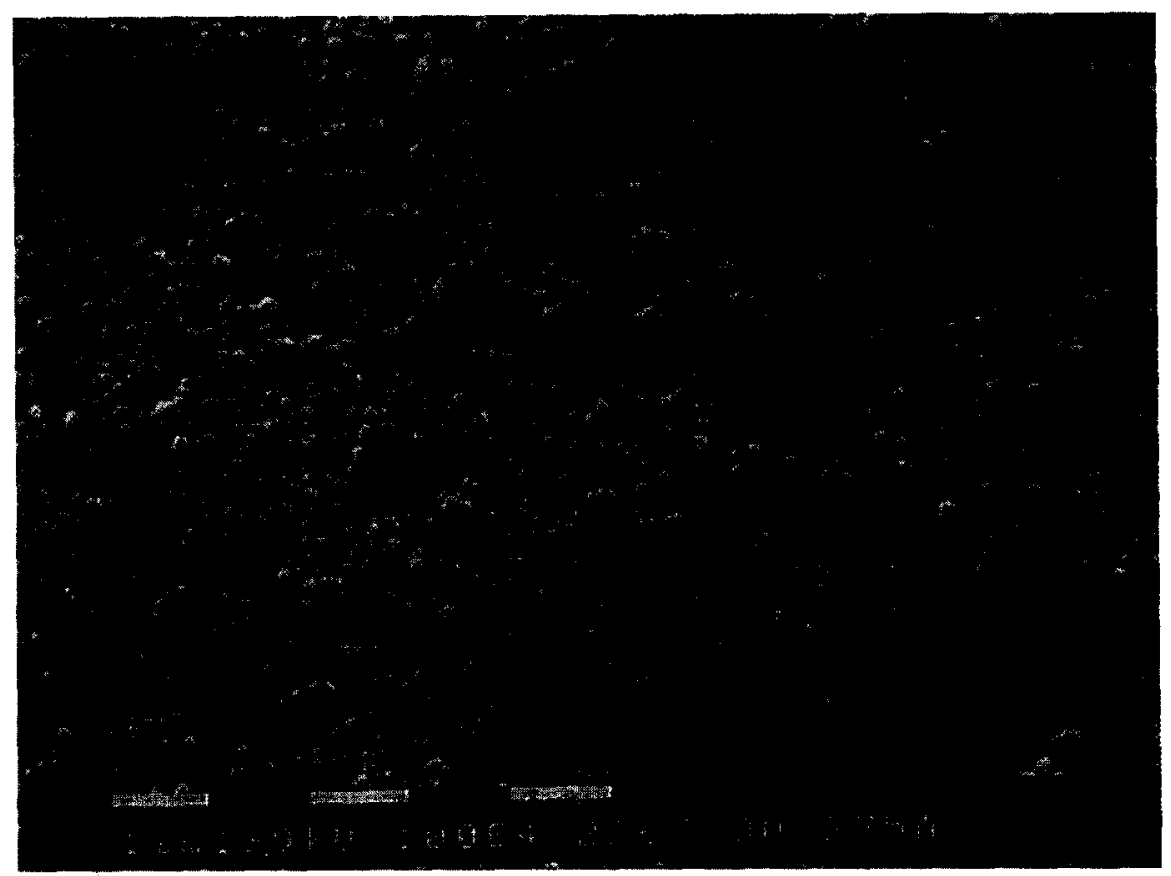

Fig. 5. Scanning electron micrographs of TS-1 samples 1. 

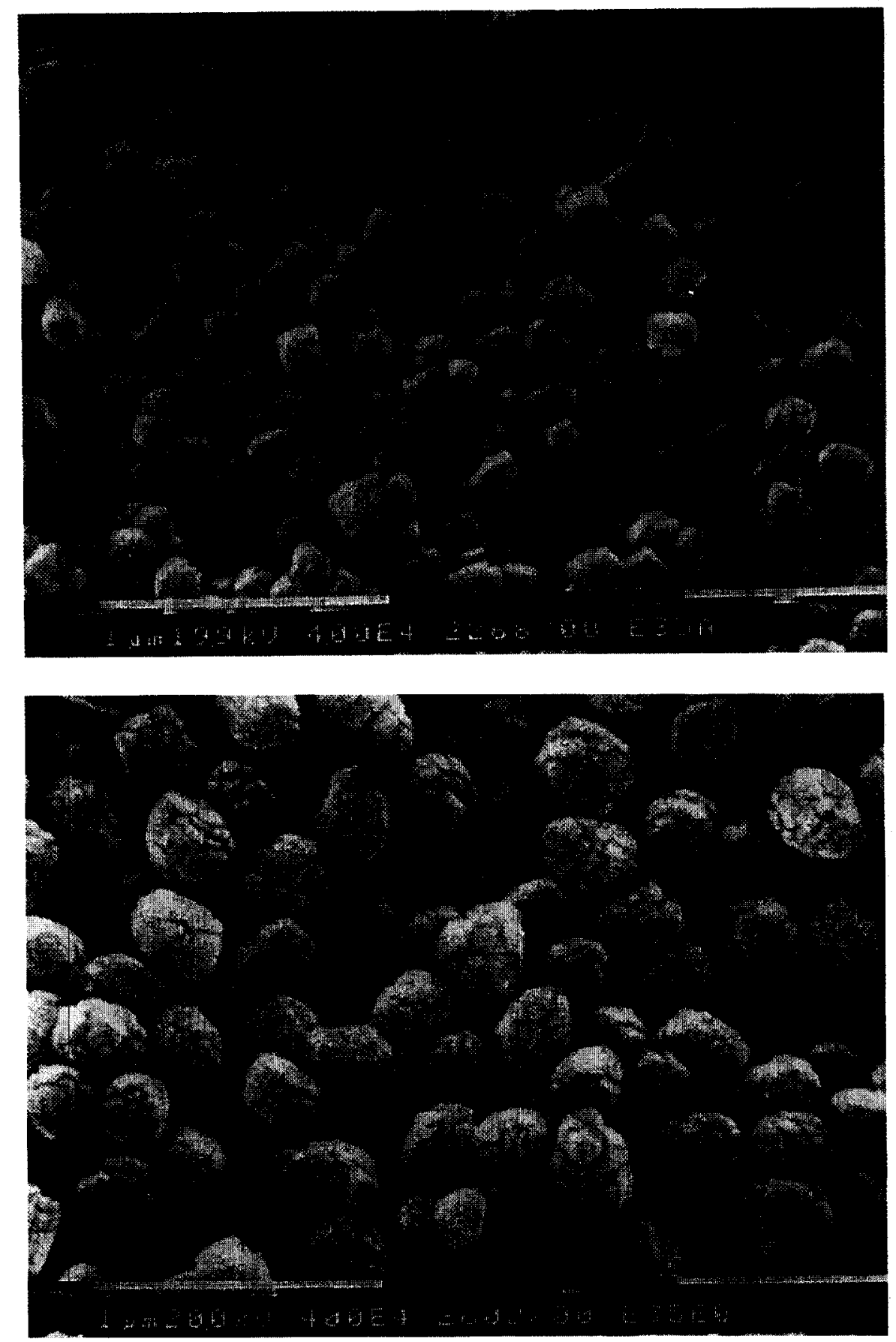

Fig. 6. SEM pictures of samples 1, 2, 3 and 4 (see also overleaf). 

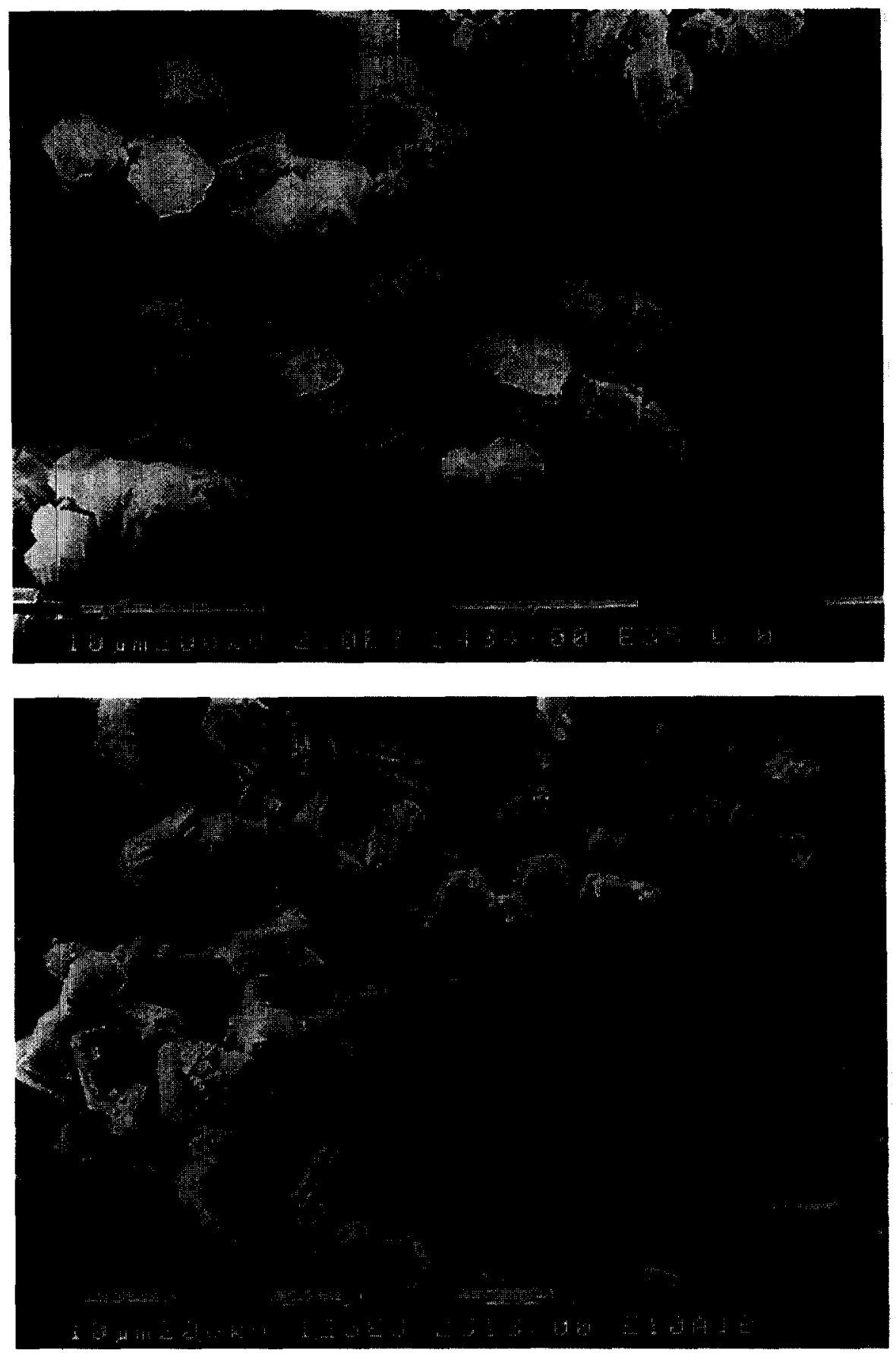

Fig. 6.(Continued). 
of samples 3 and 4 (5 and $10 \mu \mathrm{m}$, respectively) and the pictures also show differences in particle morphology. The particles of sample 1 have an almost cubic shape, the shape of sample 2 is more spherical with an irregular surface ("cauliflower" structure), while sample 3 and particularly sample 4 possess the so-called twinned coffin structure.

\section{Malvern and Coulter counter}

Information about particle sizes can also be obtained using a Malvern and Coulter Counter. The results of these methods are presented in Table 3 in which, for comparison, the average particle size as obtained by SEM is mentioned as well. Both Malvern and Coulter Counter show narrow particle size distributions of the different samples, which is in agreement with the homogeneous pictures obtained by SEM.

Furthermore there is a good agreement between average particle size as obtained from SEM pictures and the average particle size as determined by Malvern (The values obtained by Malvern are shifted to somewhat larger sizes). The fact that by Coulter Counter for samples 1 and 2 much larger values are obtained may be caused by the fact that by this technique not the size of the separate particles is determined but the size of the aggregates of particles that are present in the suspension. However, the results of all three techniques have in common that the average particle sizes of samples 1 and 2 with high catalytic activity are much smaller than the average particle sizes of sample 3 and 4 with low catalytic activity.

\section{TABLE 3}

Average particle size of TS- 1 samples 1 to 4 as determined by SEM, Malvern and Coulter Counter, as well as determination of the morphology by SEM

\begin{tabular}{lllll}
\hline Sample & SEM & $\begin{array}{l}\text { Malvern } \\
\text { average size }\end{array}$ & $\begin{array}{l}\text { Coulter counter } \\
\text { average size }\end{array}$ \\
\cline { 2 - 5 } & $\begin{array}{l}\text { Average } \\
\text { size }^{a}\end{array}$ & Morphology & & \\
\hline 1 & 0.2 & Cubic & 0.3 & 1.6 \\
2 & 0.3 & Cauliflower & 0.5 & 1.8 \\
3 & 5.0 & Coffins & 6.0 & 7.0 \\
4 & 10.0 & Coffins & 11.7 & n.d. \\
\hline
\end{tabular}

${ }^{a}$ average size in $\mu \mathrm{m}$.

${ }^{b}$ n.d. not determined 
Thermogravimetric analysis and adsorption measurements

Additional information about particle size can be obtained from TGA and adsorption measurements. Fig. 7 shows the differential thermogravimetry (DTG) pattern obtained from the crystallization product of TS-1 sample 1 . The main peak at $415^{\circ} \mathrm{C}$ with a shoulder at $460^{\circ} \mathrm{C}$ is caused by decomposition of the template present in the zeolite pores and is almost the same for all four samples. However, the small peak at $100^{\circ} \mathrm{C}$ (caused by the desorption of water) and the shoulder at $370^{\circ} \mathrm{C}$ (caused by the desorption of adsorbed template) differ strongly in intensity for the four different samples (see Table 4).

From this table it can be seen that the amount of adsorbed template is much larger for the TS-1 samples 1 and 2 than for the TS-1 samples 3 and 4, which is in agreement with the smaller particle size of these samples.

The same conclusion can be obtained from the results of the adsorption measurements. As indicated in Table 4, the amount of adsorbed n-butane decreases in the sequence sample $1 \cong$ sample $2>$ sample $3>$ sample 4 .

So all five techniques used to characterize the texture of the four TS-1 samples have in common that they indicate much smaller particle sizes for samples

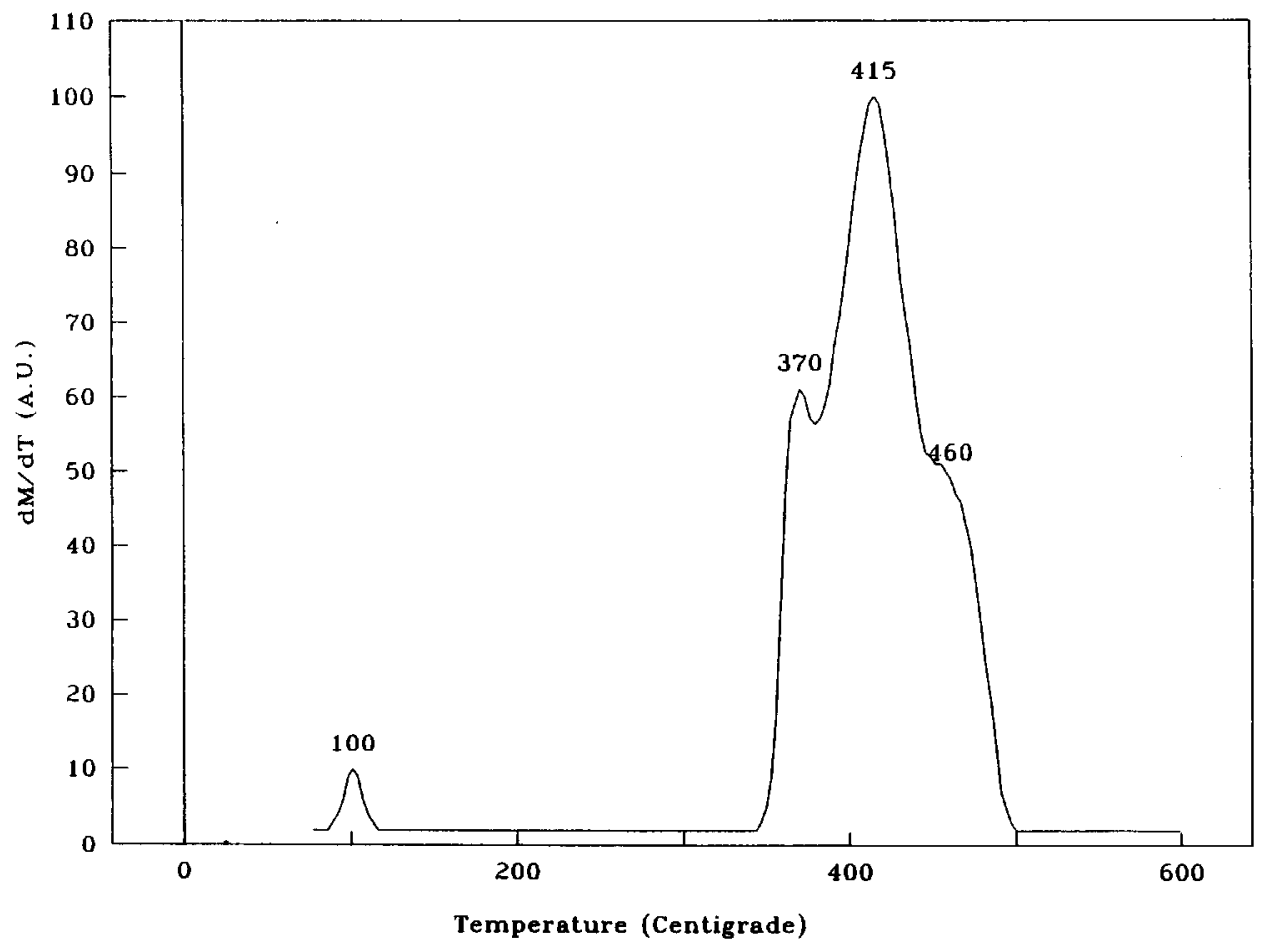

Fig. 7. DTG pattern of a TS-1 sample. 


\section{TABLE 4}

Peak area of the DTG peaks at $100^{\circ} \mathrm{C}$ and $370^{\circ} \mathrm{C}$ relative to the total peak area and the amount of $\mathrm{n}$-butane adsorbed at $p=0.1 \mathrm{~atm}$ and $T=298 \mathrm{~K}$ on the TS- 1 samples 1 to 4

\begin{tabular}{llll}
\hline Sample & $\begin{array}{l}\text { Peak } 100^{\circ} \mathrm{C} \\
(\%)\end{array}$ & $\begin{array}{l}\text { Peak } 370^{\circ} \mathrm{C} \\
(\%)\end{array}$ & $\begin{array}{l}\text { Adsorption } \\
(\mathrm{ml} / \mathrm{g})\end{array}$ \\
\hline 1 & 7.4 & 5.6 & 0.191 \\
2 & 5.0 & 5.3 & 0.188 \\
3 & 0.8 & 0.2 & 0.171 \\
4 & 0.2 & 0.0 & 0.158 \\
\hline
\end{tabular}

1 and 2 than for samples 3 and 4 ; and as already supposed above, this difference in particle size may be the reason for the observed difference in catalytic activity.

Two explanations can be put forward for the possible influence of particle size on catalytic activity. Firstly the reaction can take place mainly at the outer surface of the catalyst particles, and because smaller particles have a larger specific outer surface area this will lead to a higher activity. However the following experimental observations do not support this explanation: (i) Noncalcined samples, where the used template is still present in the pores, show low activity. (ii) Adsorption of large molecules (e.g. nonanol) in the pore system causes a strong decrease in activity. (iii) Hydroxylation activity is only observed with hydrogen peroxide; large hydroperoxide is such as tertiary butylhydroperoxide or cyclohexylhydroperoxide do not react. (iv) Only very slow reaction is observed with large substrates that cannot enter the pores.

These observations strongly suggest that the outer surface of the TS-1 particles has a small contribution to the catalytic activity and so the reaction must take place mainly inside the zeolite pores.

In view of this, the second explanation remains that the reaction is restricted by pore diffusion limitations. In this case the lower activity of catalysts with larger average particle size is caused by lower catalyst efficiency.

A method to describe the influence of pore diffusion on the observed reaction rate is given by the Weisz theory [15-18]. In this theory the Weisz modulus $(\Phi)$ and catalyst efficiency $(\eta)$ are defined as:

$\Phi=\frac{\left(\frac{p}{6}\right)^{2} \cdot R_{0}}{D_{\text {eff }} \cdot C_{0}}$ and $\eta=\frac{\tanh \Phi}{\Phi}$

where $p$ is the mean diffusion path length $(\mathrm{m}), R_{0}$ is the observed reaction rate $\left(\mathrm{mol} / \mathrm{m}^{3} \mathrm{~s}\right), D_{\text {eff }}$ is the effective diffusion coefficient of substrate $\left(\mathrm{m}^{2} / \mathrm{s}\right), C_{0}$ is the concentration of substrate at the outer surface of the catalyst $\left(\mathrm{mol} / \mathrm{m}^{3}\right)$, and $\eta$ is the catalyst efficiency $=R_{\text {observed }} / R_{\text {intrinsic }}$.

Reversely the Weisz theory can be used to check whether the observed dif- 
TABLE 5

Average diffusion path length $(p)$ as deduced from SEM pictures, as well as the (relative) Weisz modulus ( $\phi^{\prime}$ and) $\phi$ and the (relative) catalyst efficiency ( $\eta^{\prime}$ and) $\eta$ of the TS-1 samples 1 to 4

\begin{tabular}{lllllll}
\hline $\begin{array}{l}\text { Sample } \\
\text { no. }\end{array}$ & $\begin{array}{l}\text { Average } \\
\text { particle } \\
\text { size } d \\
(\mu \mathrm{m})\end{array}$ & $\begin{array}{l}\text { Average length } \\
\text { of diffusion } \\
\text { path } \boldsymbol{p}(\mu \mathrm{m})\end{array}$ & $\Phi^{\prime}$ & $\eta^{\prime}$ & $\Phi$ & $\eta$ \\
\hline 1 & 0.2 & 0.1 & 1.0 & 1.0 & 0.30 & 0.90 \\
2 & 0.3 & 0.15 & 2.0 & 0.88 & 0.60 & 0.79 \\
3 & 5.0 & 1.5 & 24 & 0.11 & 7.2 & 0.099 \\
4 & 10.0 & $\mathbf{3 . 5}$ & $\mathbf{5 5}$ & $\mathbf{0 . 0 4 5}$ & $\mathbf{1 6 . 5}$ & 0.041 \\
\hline
\end{tabular}

ferences in catalytic activity of the TS- 1 samples 1 to 4 are really caused by differences in catalyst efficiency, as a result of pore diffusion limitations.

It is therefore necessary to calculate first the values of the Weisz modulus of the four TS-1 samples. For this the values of the average length of the diffusion path $p$, the observed reaction rate $R_{0}$, the effective diffusion coefficient of phenol $D_{\text {eff }}$ and the phenol concentration at the outer surface of the catalyst particles $C_{0}$, must be known.

As is discussed by Voogd and Van Bekkum [19] for zeolites with ZSM-5 structure, half the length along the $b$-axis should be taken as the length of the diffusion path. These values can be obtained from SEM pictures as shown in Fig. 6; they are listed in Table 5.

The values of the observed reaction rate $R_{0}$ can be obtained from Fig. 4 where the conversion is plotted as function of time of reaction. For example the initial rate of reaction can be obtained, as was done for compiling Table 2 .

It is more difficult to estimate correct values for the surface concentration $C_{0}$ of phenol under reaction conditions, and especially for the effective diffusion coefficient $D_{\text {eff }}$ of phenol. From the literature [20-22] it is found that the reported values of diffusion coefficients may very well vary two orders of magnitude. Also the surface concentration of phenol $\left(C_{0}\right)$ is difficult to measure.

As the values of $C_{0}$ and $D_{\text {eff }}$ will be almost the same for the different catalytic experiments it is, however, possible to eliminate $C_{0}$ and $D_{\text {eff }}$ by introducing a relative Weisz modulus $\Phi^{\prime}$ according to:

$$
\Phi^{\prime}(2)=\frac{\Phi(2)}{\Phi(1)}=\frac{\frac{\left(\frac{p(2)}{6}\right)^{2} \cdot R(2)_{0}}{D_{\text {eff }} \cdot C(2)_{0}}}{\frac{\left(\frac{p(1)}{6}\right)^{2} \cdot R(1)_{0}}{D_{\text {eff }} \cdot C(1)_{0}}} \cong \frac{p^{2}(2) \cdot R(2)_{0}}{p^{2}(1) \cdot R(1)_{0}}
$$


and because the intrinsic reaction rate will be the same for all experiments it is also possible to introduce in a comparable way a relative efficiency $\eta^{\prime}$ :

$\eta^{\prime}(2)=\frac{\eta_{2}}{\eta_{1}}=\frac{\frac{R(2)_{0}}{R_{\text {intr }}}}{\frac{R(1)_{0}}{R_{\text {intr }}}} \cong \frac{R(2)_{0}}{R(1)_{0}}$

The values of the relative Weisz modulus $\Phi^{\prime}$ and the relative catalyst efficiency $\eta^{\prime}$ of the four TS-1 samples obtained in this way are presented in Table 5.

According to the theory the relation between the relative Weisz modulus $\Phi^{\prime}$ and the relative catalyst efficiency $\eta^{\prime}$ (the relative Weisz plot) should have the same form as the theoretical Weisz plot. As shown in Fig. 8 the data points $1^{\prime}$, $2^{\prime}, 3^{\prime}$ and $4^{\prime}$ representing the values of $\Phi^{\prime}$ and $\eta^{\prime}$ of the four TS-1 samples 1 to 4 are indeed positioned on a curve parallel to the theoretical Weisz plot.

Because of the similarity of the relative Weisz plot and the theoretical Weisz plot it must also be possible to translate the relative Weisz plot in such a way that it fits the theoretical Weisz plot. As indicated in Fig. 8 this can be obtained by a translation vector of ${ }^{*} 0.90$ for $\eta^{\prime}$ and ${ }^{*} 0.3$ for $\Phi^{\prime}$. The fact that the translated data points $1,2,3$, and 4 show a reasonable fit with the theoretical

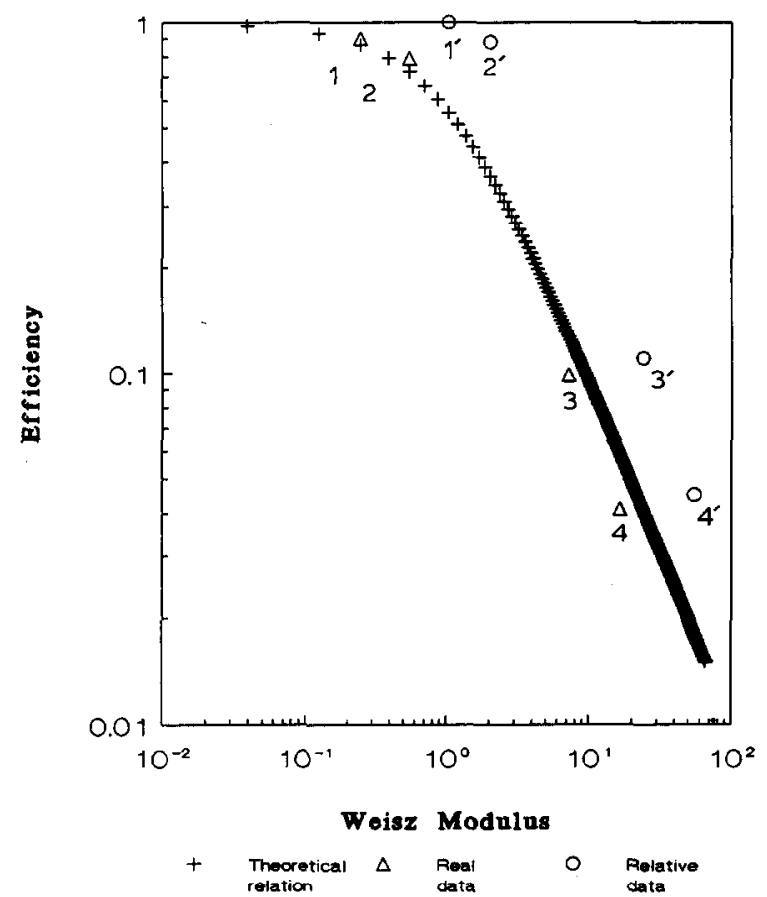

Fig. 8. Theoretical Weisz plot ( $\eta$ versus $\Phi$ ) and the relative Weisz plot ( $\eta^{\prime}$ versus $\phi^{\prime}$ ). 
Weisz plot indicates that the Weisz theory gives an adequate explanation for the observed particle size effect on activity.

The translation of the relative Weisz plot to fit the theoretical Weisz plot makes it also possible to estimate the real values of the Weisz modulus $\Phi$ and the catalytic efficiency $\eta$ of the four TS-1 samples. These values are indicated by the data points 1,2,3 and 4 in Fig. 8 and are also listed in Table 5.

Knowing the real values of the Weisz modulus makes it also possible to estimate a value for the effective diffusion coefficient of phenol $\left(D_{\text {eff }}\right)$ under reaction conditions. Using the values listed in Table 5 for TS- 1 sample 1 and assuming that the phenol concentration at the outer surface $\left(C_{0}\right)$ is equal to the bulk concentration $=4.8 \cdot 10^{3} \mathrm{~mol} / \mathrm{m}^{3}$, this results in:

$\Phi=\frac{\left(\frac{p(1)}{6}\right)^{2} \cdot R(1)_{0}}{D_{\text {eff }} \cdot C_{0}}=\frac{\left(\frac{0.1 \cdot 10^{-6}}{6}\right)^{2} \cdot 10.2}{D_{\text {eff }} \cdot 4.8 \cdot 10^{3}}=0.3$

and therefore: $D_{\text {eff }} \cong 2 \cdot 10^{-18} \mathrm{~m}^{2} / \mathrm{s}$. Although this value will not be very accurate it is in the same order of magnitude as the diffusion coefficients that are reported in the literature for comparable molecules like benzene and xylene in MFI zeolites [20-22].

The results discussed so far had to do with the influence of particle size on catalytic activity but particle size also effects product selectivity and product yield.

As already indicated in Table 2 the dihyroxybenzene selectivity after $1 \mathrm{~h}$ of reaction, and the dihydroxybenzene yield at complete reaction are much higher for TS- 1 samples 1 and 2 than for samples 3 and 4 .

The explanation of this observation can be similar to the explanation of the differences in activity. In the case that catalysts with small particle size are used (samples 1 and 2) a rapid reaction to the desired products (hydroquinone and catechol) will occur, resulting in a rapid consumption of the hydrogen peroxide, so little time will be available for hydrogen peroxide to form unwanted by-products (e.g. paraquinone and tar) or to decompose to form molecular oxygen. On the other hand if catalysts with large particle sizes are used (samples 3 and 4) hydrogen peroxide consumption will be slow, leaving ample time for unwanted parallel and consecutive reactions.

Summarizing it can be concluded that the use of TS-1 catalysts with small particle size is necessary to obtain high activity and this high activity is in turn necessary to obtain high product yield. The correctness of this conclusion can be illustrated by Fig. 9 in which high product yields were obtained if catalysts with small particle size were used, while application of catalysts with large particle size resulted in low product yield. 


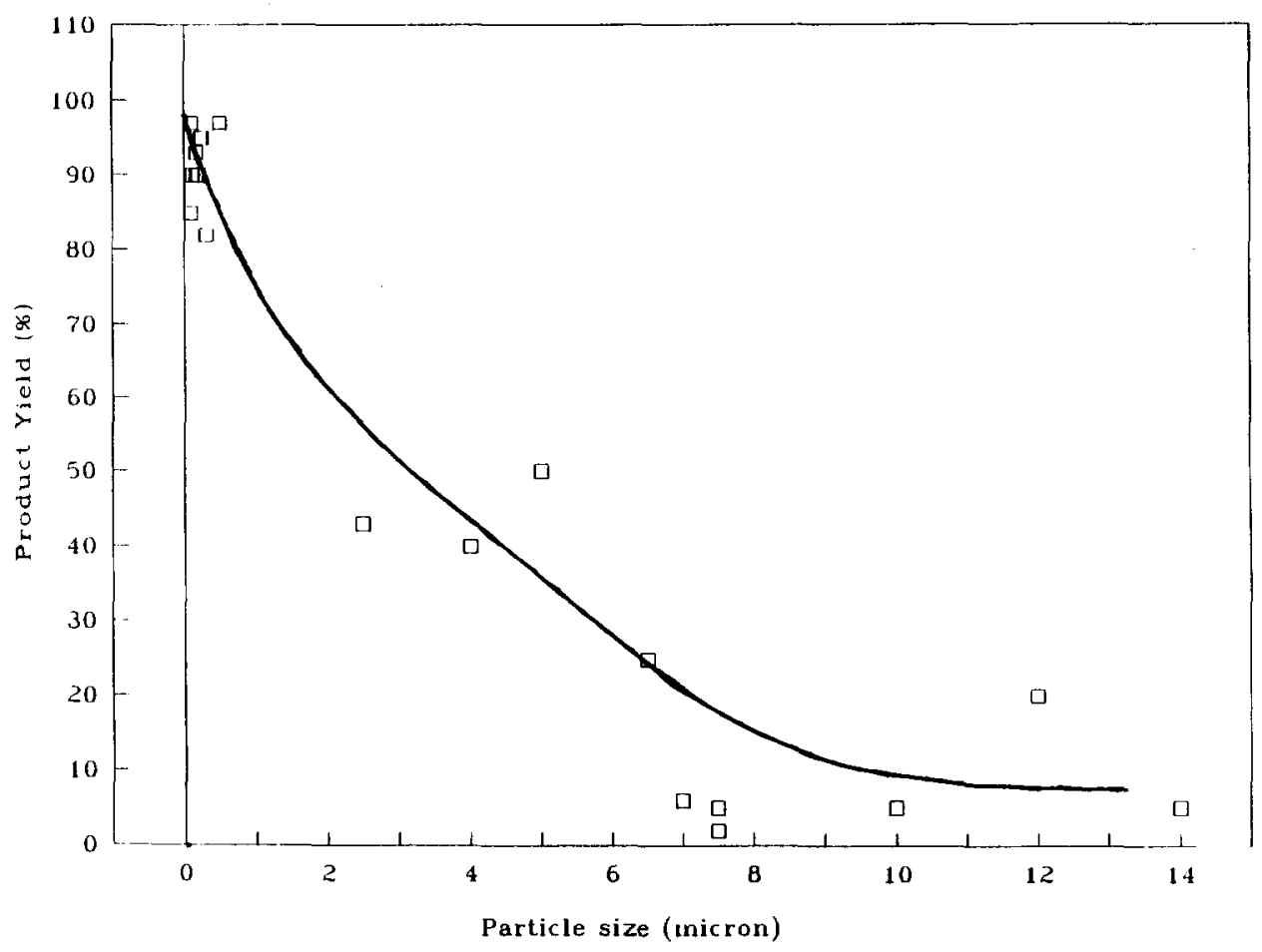

Fig. 9. Product yield versus the particle size.

\section{CONCLUSIONS}

- By application of method 1 of the Enichem patent highly crystalline TS1 with uniform particle size could be synthesized.

- By the standard characterization techniques XRD, IR, ${ }^{29} \mathrm{Si}$ MAS NMR, and DREAS it is impossible to distinguish between active and less active catalysts for the hydroxylation of phenol.

- Catalytic activity strongly depends on catalyst particle size as determined directly by SEM, Malvern or Coulter Counter, or indirectly by TGA and adsorption measurements.

- The higher activity of smaller catalysts particles is not caused by a larger contribution of the outer surface of the catalyst particles but by a higher catalyst efficiency as a result of less pore diffusion limitation.

- The results obtained by four catalysts of different particle size can be described by the Weisz theory. From this it can be deduced that catalyst particles smaller than about $0.3 \mu \mathrm{m}$ are needed to obtain catalyst efficiency above $90 \%$. 
- Numerical evaluation of the Weisz modulus makes it possible to estimate a value of $2 \cdot 10^{-18} \mathrm{~m}^{2} / \mathrm{s}$ for the effective diffusion coefficient of phenol in TS1 under reaction conditions.

- TS- 1 catalysts with small particle size $(<0.3 \mu \mathrm{m})$ are needed to obtain high activity and high product yield.

\section{ACKNOWLEDGEMENT}

The authors thanks the Netherlands Organization of Scientific Research (N.W.O.-S.T.W.) for financial support.

\section{REFERENCES}

1 M. Taramasso, G. Perego and B. Notari, US Patent 4410501 (1983).

2 C. Neri and F. Buonomo, Eur. Patent 0100117 A1 (1984).

3 A. Esposito, C. Neri and F. Buonomo, Eur. Patent 0102655 A2 (1984).

4 T. Tatsumi, M. Nakamura, S. Nagishi and H. Tominaga, J. Chem. Soc., Chem. Commun., (1990) 476-477.

5 D.R.C. Huybrechts, L. De Bruyker and P.A. Jacobs, Nature (London), 345 (1990) 242-243.

6 M.G. Clerici and U. Romano, Eur. Patent 0230949 A2 (1987).

7 C. Neri, B. Anfossi and F. Buonomo, Eur. Patent 0100119 A1 (1983).

8 C. Neri and F. Buonomo, Eur. Patent 0102097 B1 (1986).

9 P. Roffia and M. Padovan, Eur. Patent 0208311 A2 (1987)

10 B. Notari, in P.J. Grobet, W.J. Mortier, E.F. Vansant and G. Schulz-Ekloff (Editors), Innovation in Zeolite Materials Science (Studies in Surface Science and Catalysis, Vol. 37), Elsevier, Amsterdam, 1987, pp. 413-425.

11 R.A. Sheldon, in G. Centi and F. Trifiró (Editors), New Developments in Selective Oxidation (Studies in Surface Science and Catalysis, Vol. 55), Elsevier, Amsterdam, 1990, pp. 1-32.

12 A. Thangaraj, R. Kumar and P. Ratnasamy, J. Catal., 131 (1990) 294-297.

13 A.J.H.P. van der Pol and J.H.C. van Hooff, Appl. Catal, 92 (1992) 93-111.

14 M.R. Boccuti, K.M. Rao, A. Zecchina, G. Leofanti and G. Petrini, in C. Morterra, A. Zecchina and G. Costa (Editors), Structure and Reactivity of Surfaces (Studies in Surface Science and Catalysis, Vol. 48), Elsevier, Amsterdam, 1989, pp. 133-144.

15 O. Levenspiel, in O. Levenspiel (Editor), Chemical Reaction Engineering, Wiley, New York, 1972, pp. 469-483.

16 W.O. Haag, R.M. Lago and P.B. Weisz, Faraday Discuss., 72 (1981) 317-330.

17 P.B. Weisz, ChemTech, (August 1973) 504.

18 J.F. Marshall and P.B. Weisz, J. Catal., 111 (1988) 460-463.

19 P. Voogd and H. Van Bekkum, Appl. Catal., 59 (1990) 311-331.

20 H.J. Doëlle, J. Heering and L. Riekert, J. Catal., 71 (1981) 27-40.

21 W.R. Quereshi and J. Wei, J. Catal., 126 (1990) 147-172.

22 D.B. Shah, D.T. Hayhurst, G. Evanine and G.J. Guo, AIChE J., 34 (1988) 1713. 